Benchmarks

\title{
An assay for small scale screening of candidate $\beta$ cell proliferative factors using intact islets
}

\author{
Rockann E. Mosser ${ }^{1,2}$ and Maureen Gannon ${ }^{1,2,3,4}$ \\ ${ }^{1}$ Department of Veterans Affairs Tennessee Valley, Nashville, TN. \\ Department of ${ }^{2}$ Medicine, ${ }^{3}$ Cell and Developmental Biology, ${ }^{4}$ Molecular \\ Physiology and Biophysics, Vanderbilt University, Nashville, TN.
}

BioTechniques 55:310-312 (December 2013) doi 10.2144/000114115

Keywords: $\beta$ cell; proliferation; screening assay

Supplementary material for this article is available at www.BioTechniques.com/article/114115.

Current protocols for screening proliferative factors for $\beta$ cells ex vivo are timeconsuming, require cell lines or dissociated islets, and often entail expensive specialized screening equipment. Here we present an efficient and lower cost alternative that utilizes intact mouse islets for the initial screening of proliferative compounds and allows confirmation of $\beta$ cell proliferation from the same islets. This protocol simplifies the process, saves money, and provides a way to identify $\beta$ cell proliferative factors using equipment that is ubiquitous in most laboratories.

Diabetes mellitus is a disease of the insulin producing $\beta$ cell, which functions under normal physiological conditions to maintain glucose homeostasis. With diabetes diagnoses on the rise, investigations into chemical and biological factors that expand $\beta$ cell mass through $\beta$ cell proliferation have increased. In vivo experiments require injections of potential proliferative compounds followed by pancreata dissection, embedding, sectioning, and immunolabeling. This process is expensive and laborious, which is why conducting an initial ex vivo $\beta$ cell proliferative factor screen is beneficial; however, the few protocols that exist rely on expensive and specialized equipment and imaging software $(1,2)$. Furthermore, existing protocols first screen compounds in dissociated islets or $\beta$ cell lines and then verify activity with intact islets, which is time-consuming and problematic. For example, dissociated islets and $\beta$ cell lines lack the crucial islet architecture that is important for proper $\beta$ cell response and may lack critical cell surface receptors, contributing to missed proliferative factors $(3,4)$. Conversely, intact islets are more biologically relevant but are also difficult to isolate, culture, and process for histology following exposure to compound(s).

To improve upon existing assays, we have developed an efficient small scale screening method for $\beta$ cell proliferative factors that utilizes intact islets for the initial screening and then dissociates those same islets to assess $\beta$ cell proliferation (Figure 1). The primary screen described here has been developed to identify potential $\beta$ cell prolifislets opens up the possibility of identifying potential $\alpha, \delta, \varepsilon$, and PP cell proliferative stimuli.

$\beta$ cells progress through the cell cycle very slowly; therefore, most ex vivo $\beta$ cell proliferation assays include a $96 \mathrm{~h}$ incubation period in order to detect a proliferative effect $(5,6)$. Due to this slow replication rate, special effort was taken to shorten the amount of time between discovery erative factors; however, the use of whole and confirmation of potential proliferative factors by utilizing the same islets for both screening and verification. The non-toxic cell viability reagent resazurin/ alamar blue (\#DAL1025, Invitrogen, Grand Island, NY) is reduced to the fluorescently detectable compound resorufin in the presence of living cells. Resazurin has been used to identify changes in cell number in numerous cell lines including INS-1 cells and primary islets $(7,8)$. To determine if the resazurin reaction would be sensitive enough to detect small fluctuations in islet mass, an islet standard curve consisting of $0,5,10,25$, and 40 islet equivalents (IEQs) (9), each in $100 \mu \mathrm{L}$ media (RPMI 1640 , $10 \%$ horse serum, $11 \mathrm{mM}$ glucose, $100 \mathrm{U} /$ $\mathrm{mL}$ penicillin, and $100 \mu \mathrm{g} / \mathrm{mL}$ streptomycin) was distributed into 96-well tissue culture plates (\#3603, Corning, Corning, NY). Four wells with variable IEQs were included for validation of the assay (Figure $2 \mathrm{~A})$. Resazurin $(10 \mu \mathrm{L})$ was incorporated into each well and fluorescence output $\left(\lambda_{\mathrm{Ex}} 535 \pm 9 / \lambda_{\mathrm{Em}} 595 \pm 9\right)$ was measured with a Synergy H4 plate reader (BioTek, Winooski, VT) after a $4 \mathrm{~h}$ incubation at $37^{\circ} \mathrm{C}$ and $5 \% \mathrm{CO}_{2}$. A linear relationship between fluorescence signal and standard curve IEQs was observed and used to derive the estimated IEQ figures from the variable samples, which agreed remarkably well with the measured IEQs (Figure 2A). From this, we determined that resazurin was sensitive enough to detect small differences in islet mass.

The inherent structure of islets makes it difficult for nutrients and other compounds to diffuse to the internal core of the islet ex vivo, which can result in internal islet cell death. A method for adenoviral transduction of intact ex vivo islets transiently adds EGTA to mildly disrupt cell to cell contacts throughout the islet, thereby increasing efficiency of adenoviral gene transfer to the internal aspect of the islet (10). Borrowing this concept, we tested if the addition of EGTA would enhance access to the islet core without disrupting adhesion of islets to the culture plate. Twenty IEQs were incubated for $24 \mathrm{~h}$ in media with or without $0.1 \mathrm{mM}$ EGTA and assayed as above (Figure 2B). Placental lactogen (PL), a known $\beta$ cell mitogen, was utilized as a positive $\beta$ cell proliferative control $(5,7)$. Interestingly, addition of EGTA alone induced a 1.5 -fold increase in resorufin signal, and addition of EGTA plus PL enhanced the signal an additional 1.3 -fold (Figure 2B). The lack of resorufin signal in

Method summary: This method utilizes common reagents and equipment to assess potential $\beta$ cell proliferative compounds in intact mouse islets. Employing the same islets for the initial screening of compounds and for the final validation of enhanced $\beta$ cell proliferation saves time, requires fewer animals and less effort, and is more cost-effective than existing protocols. 


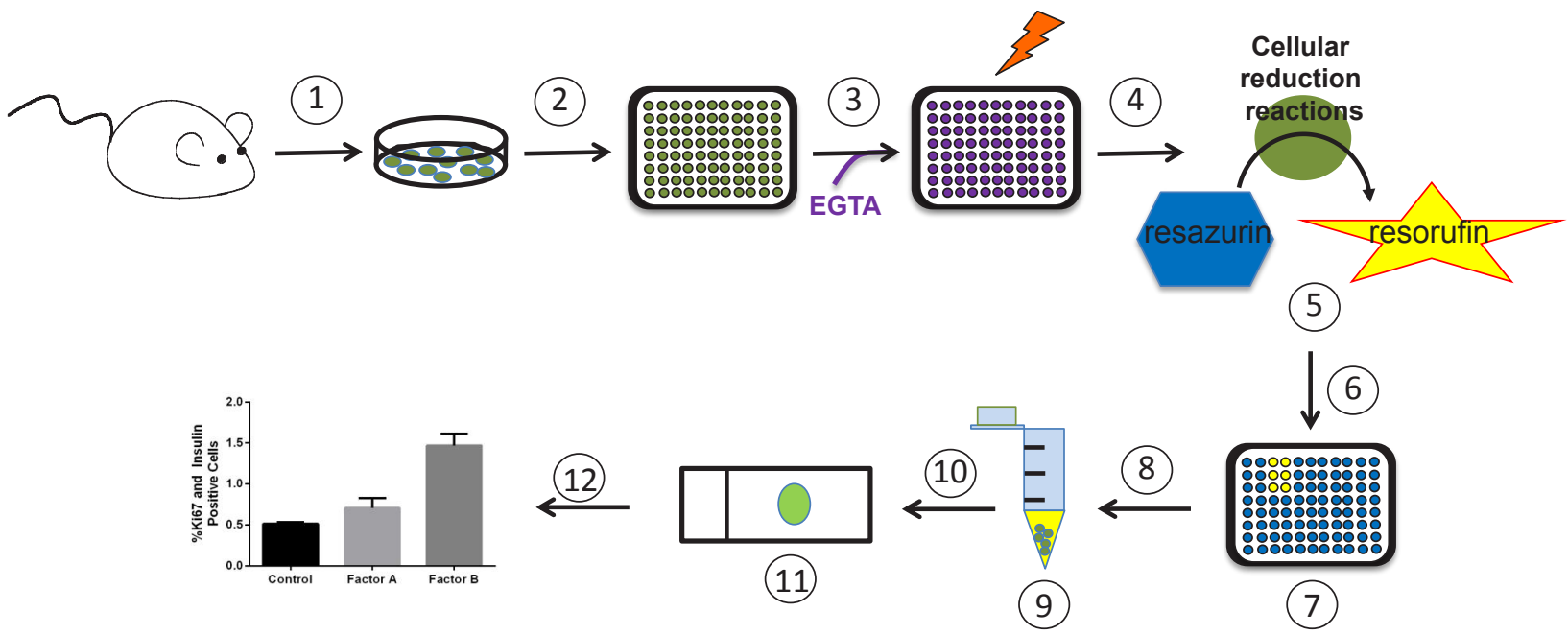

Figure 1. Experimental scheme for the $\beta$ cell proliferative factor assay. (1) Isolate islets. (2) Divide islets evenly into a 96-well plate and culture overnight. (3) Replace media with new media supplemented with EGTA and potential proliferative factors (or vehicle control). (4) Incubate $96 \mathrm{~h}$ with a media change at $48 \mathrm{~h}$. (5) Add resozurin and incubate $4 \mathrm{~h}$. (6) Determine fluorescence with plate reader. (7) Wells with elevated fluorescence readings when compared with control readings are potential hits. (8) For hit and corresponding control wells: remove media, trypsinize, and transfer dissociated islets to tubes. (9) Neutralize trypsin, pellet dissociated islets, remove supernatant, and add media. (10) Distribute dissociated islets onto a charged microscope slide using a cytofunnel and cytospin. (11) Immunolabel dissociated islets for insulin and proliferative marker. (12) Quantify $\beta$ cell proliferation.
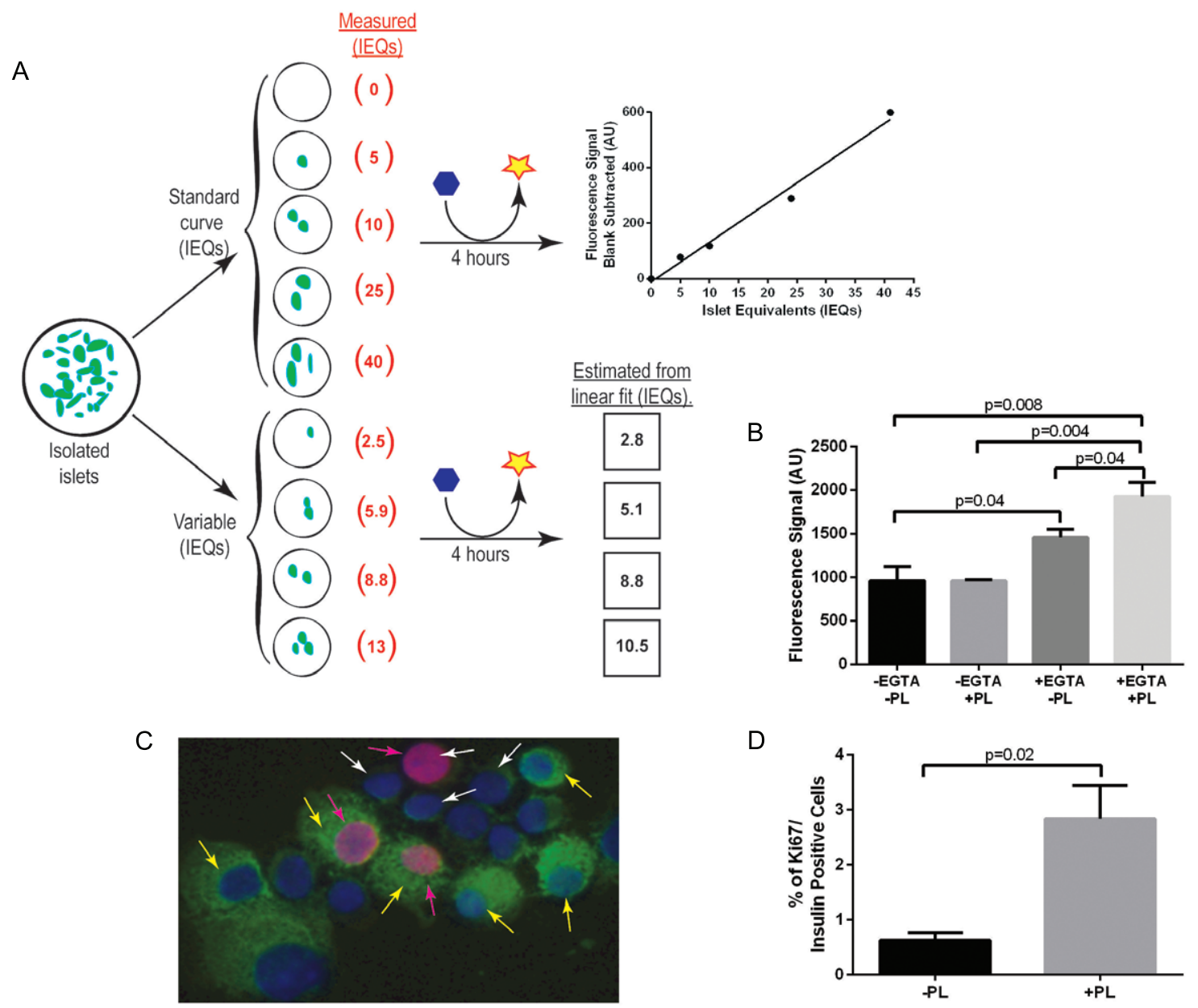

Figure 2. Validation of the $\beta$ cell proliferative factor assay. (A) Setup and rationale for the resozurin screening of intact islets from 8 week old male and female $\mathrm{C} 57 \mathrm{BI} / 6 \mathrm{~J}$ mice (green ovals represent islets, blue hexagons represent resozurin, and yellow stars represent resorufin). (B) The resorufin fluorescence signal is enhanced after a $24 \mathrm{~h}$ incubation with 20 IEQ in media supplemented with $0.1 \mathrm{mM} \mathrm{EGTA}$ and/or $0.5 \mu \mathrm{g} / \mathrm{mL} \mathrm{PL}(\mathrm{n}=3-4)$. (C) Depiction of dissociated islets immunolabeled with insulin (green), Ki67 (pink), and DAPI (blue). The white arrows indicate non- $\beta$ cells, pink arrows indicate proliferating cells, and yellow arrows indicate $\beta$ cells. (D) Quantification results of insulin and Ki67 immunolabeling confirming the results of the resozurin assay showing enhanced $\beta$ cell proliferation in the presence of PL. Data are shown as mean \pm SEM $(n=3-4)$; $P$-values were calculated using the unpaired $t$-test. 
the sample treated with PL alone was not surprising due to the shorter incubation period used in this study versus previously published studies ( $24 \mathrm{~h}$ instead of $96 \mathrm{~h}$ ) (5). From this, we concluded that the addition of EGTA promotes access of nutrients and mitogens in the media to the internal aspect of the islet, thus facilitating a more robust proliferative response. Therefore, in the current protocol, freshly isolated islets were equally divided into a 96-well plate and cultured overnight in the absence of EGTA to allow islets to rest and adhere completely to plates. The next day, fresh media supplemented with EGTA and potential mitogens were added. Cultures were replenished with fresh media after $48 \mathrm{~h}$. After a total $96 \mathrm{~h}$ of incubation, the resazurin reaction was performed and detected as described above.

To determine if the increase in resorufin fluorescence was due to $\beta$ cell proliferation, islets from individual wells of interest were dissociated into single cell suspensions for further analyses. These analyses also explored whether an increase in resorufin fluorescence was due to an effect of EGTA itself, an increase in cellular metabolism, or an increase in proliferation of another islet cell type. First, media was removed and the islets gently washed with $200 \mu \mathrm{L}$ PBS. Then $100 \mu \mathrm{L}$ of a $0.025 \%$ Trypsin, $2 \mathrm{mM}$ EDTA solution was added at room temperature (RT). Trypsinized islets were pipetted up and down every 2 min until islets were visually confirmed with a microscope to be single cells. Two-hundred $\mu \mathrm{l}$ of media was then added to stop the trypsin reaction. The cells were transferred to individual $1.5 \mathrm{~mL}$ Eppendorf tubes and another $200 \mu \mathrm{L}$ of media were added to each tube before centrifuging for $5 \mathrm{~min}$ at $1,000 \mathrm{rpm}$ and $4^{\circ} \mathrm{C}$. The supernatant was discarded, the pellet resuspended in $200 \mu \mathrm{L}$ of media, and the cells transferred onto a charged slide using an EZ cytofunnel (cat. A78710003, Thermoscientific, Asheville, NC) and a cytospin centrifuge (Shandon 4, Thermoscientific). The transferred cells were air-dried at RT for $10 \mathrm{~min}$ then fixed in $4 \%$ paraformaldehyde at RT for 10 min. After a PBS wash, cells were permeabilized with $0.2 \%$ Triton$\mathrm{X} 100$ for $10 \mathrm{~min}$. The slides were immunolabeled for insulin (guinea pig,1:500, DAKO, Carpinteria, CA) and Ki67 (rabbit, 1:500, AbCam, Cambridge, MA), scanned, and quantified for $\beta$ cell proliferation as previously described (11). Ki67 is a common marker of proliferating cells (12); and is used here in conjunction with insulin labeling to identify actively proliferating $\beta$ cells. Islet cells other than $\beta$ cells could also be co-labeled with $\mathrm{Ki} 67$ at this point to assay for proliferation; however, a larger IEQ per well would be required in order to obtain a significant number of non- $\beta$ cells to quantify, since $\beta$ cells make up nearly $85 \%$ of the rodent islet mass. With this method, $\beta$ cells and proliferating cells are distinguishable from non- $\beta$ cells and non-proliferating cells (Figure $2 \mathrm{C}$ ). Importantly, the enhanced resorufin fluorescence signal was corroborated by a 4.5-fold increase in $\mathrm{Ki} 67$ / insulin double-positive cells (Figure 2D).

In conclusion, the technique described here provides an efficient and accessible primary screen to identify potential $\beta$ cell proliferative factors using intact islets. Also, this method could easily be adapted for identification of factors that affect other islet cell types by immunolabeling for different hormones. This approach could inform directed secondary screens (including screens in vivo) in order to validate whether candidate factors can indeed expand $\beta$ cell mass. By modifying a few simple, but key, aspects of existing methods, this protocol offers exciting prospects for discovery of new islet cell mitogens.

\section{Author Contributions}

R.E.M. designed experiments, conducted the research, and wrote the paper. M.G. acted as a consultant on the study and edited the paper.

\section{Acknowledgments}

We would like to thank Raymond Pasek for critical reading of the manuscript. We would like to thank Danielle Dean and members of the Gannon lab for helpful discussions, and Anastasia Coldren for islet isolations. All mice were maintained and experiments conducted in accordance with protocols approved by the Vanderbilt Institutional Animal Care and Use Committee under the supervision of the Division of Animal Care. Islet isolations and slide scanning was performed in the Islet Procurement and Analysis Core of the Vanderbilt Diabetes Research and Training Center supported by NIH grant DK20593. This work was funded by grants from the Veterans Administration (1BX000990-01A1) and Juvenile Diabetes Research Foundation (17-2012-26) to M.G. This paper is subject to the NIH Public Access Policy.

\section{Competing interests}

The authors declare no competing interests.

\section{References}

1. Wang, W., J.R. Walker, X. Wang, M.S. Tremblay, J.W. Lee, X. Wu, and P.G. Schultz. 2009. Identification of small-molecule inducers of pancreatic $\beta$-cell expansion. Proc. Natl. Acad. Sci. USA 106:1427-1432.
2. Shen, W., M.S. Tremblay, V.A. Deshmukh, W. Wang, C.M. Filippi, G. Harb, Y.-q. Zhang, A. Kamireddy, et al. 2013. SmallMolecule Inducer of $\beta$ Cell Proliferation Identified by High-Throughput Screening. J. Am. Chem. Soc. 135:1669-1672.

3. Chowdhury, A., O. Dyachok, A. Tengholm, S. Sandler, and P. Bergsten. 2013. Functional differences between aggregated and dispersed insulin-producing cells. Diabetologia 56:15571568.

4. Green, I.C., C. Southern, and K. Ray. 1990. Mechanism of action of growth-hormonereleasing hormone in stimulating insulin secretion in vitro from isolated rat islets and dispersed islet cells. Horm. Res. 33:199-204.

5. Zhang, H., J. Zhang, C.F. Pope, L.A. Crawford, R.C. Vasavada, S.M. Jagasia, and M. Gannon. 2010. Gestational diabetes mellitus resulting from impaired beta-cell compensation in the absence of FoxM1, a novel downstream effector of placental lactogen. Diabetes 59:143-152.

6. Hussain, M.A., D.L. Porras, M.H. Rowe, J.R. West, W.J. Song, W.E. Schreiber, and F.E. Wondisford. 2006. Increased pancreatic beta-cell proliferation mediated by CREB binding protein gene activation. Mol. Cell. Biol. 26:7747-7759.

7. Meng, F., A. Abedini, A. Plesner, C.B. Verchere, and D.P. Raleigh. 2010. The flavanol (-)-epigallocatechin 3-gallate inhibits amyloid formation by islet amyloid polypeptide, disaggregates amyloid fibrils, and protects cultured cells against IAPP-induced toxicity. Biochemistry 49:8127-8133.

8. Li, X., H. Chen, and P.N. Epstein. 2004. Metallothionein protects islets from hypoxia and extends islet graft survival by scavenging most kinds of reactive oxygen species. J. Biol. Chem. 279:765-771.

9. Ricordi, C. 1991. Quantitative and qualitative standards for islet isolation assessment in humans and large mammals. Pancreas 6:242-244.

10. Muniappan, L. and S. Ozcan. 2009. Adenoviral gene transfer into isolated pancreatic islets. Methods Mol. Biol. 590:131-142.

11. Golson, M.L., A.A.Misfeldt, U.G. Kopsombut, C.P. Petersen, and M. Gannon. 2010. High Fat Diet Regulation of $\beta$-Cell Proliferation and $\beta$-Cell Mass. The Open Endocrinology Journal 4:66-77.

12. Schlüter, C., M. Duchrow, C. Wohlenberg, M.H. Becker, G. Key, H.D. Flad, and J. Gerdes. 1993. The cell proliferation-associated antigen of antibody Ki-67: a very large, ubiquitous nuclear protein with numerous repeated elements, representing a new kind of cell cycle-maintaining proteins. J. Cell Biol. 123:513-522.

Received 30 August 2013; accepted 04 November 2013.

Address correspondence to Rockann Mosser, Department of Medicine, Division of Diabetes, Endocrinology, and Metabolism, Vanderbilt University, Nashville, TN. E-mail: rockann.e.mosser@ vanderbilt.edu

To purchase reprints of this article, contact: biotechniques@fosterprinting.com. 